\title{
ESTUDOS GEOTÉCNICOS EM BOÇOROCA NA CIDADE DE SÃO PEDRO, SÃO PAULO (SP)
}

\author{
Jair SANTORO \\ Vicente José FULFARO
}

\section{RESUMO}

\begin{abstract}
Estudamos neste trabalho uma boçoroca localizada no município de São Pedro, que está situado na região centro-leste do Estado de São Paulo, através da caracterização geotécnica dos sedimentos onde ocorre, analisaram-se os fatores influentes no processo erosivo e estabeleceu-se a contribuição de certas feições e características observadas, tanto no campo como em laboratório, que interferem na gênese e evolução das erosões aceleradas. Os sedimentos analisados apresentam homogeneidade granulométrica, baixos valores de parâmetros de resistência ao cisalhamento e valores relativamente elevados dos índices de vazios. Os valores da permeabilidade $\left(\mathrm{K}_{20}{ }^{\circ}\right)$ estão em torno de $4,27 \times 10^{-3} \mathrm{~cm} / \mathrm{s}$ e os da porosidade, $42 \%$. Quanto aos limites de consistência, as amostras caracterizam-se como não plásticas.
\end{abstract}

\section{ABSTRACT}

This paper deals with prevention and/or correction of areas susceptible of gully erosion (boçorocas), starting with the diagnosis of the phenomenon through geological as well as geomorphological and geotechnical methods. The sediments of a boçoroca, located in the municipality of São Pedro, central-eastern São Paulo State, were studied both in field and in the laboratory, from the viewpoint of susceptibility to erosion. The following characteristics were evinced: a) granulometric homogeneity; b) low values of the shear-strength parameters; c) high void rations; d) permeability values $\left(\mathrm{K}_{20}{ }^{\circ}\right)$ distributed around $\left.4,27 \times 10^{-3} \mathrm{~cm} / \mathrm{s} ; \mathrm{e}\right)$ porosity values around $42 \%$. As to the Atterberg limits the samples are considered as non plastic.

\section{INTRODUÇÃO}

No Estado de São Paulo, a erosão vem gerando pesados prejuízos para a sociedade, através da perda tanto dos solos agricultáveis, quanto de investimentos públicos em obras de infra-estrutura, visando à recuperação de áreas urbanas ou em urbanização degradadas pela erosão (DAEE-IPT, 1990).

A expressão mais flagrante da erosão é a boçoroca: intensa, profunda e acelerada erosão que rasga o solo.

As boçorocas são formas de ravinamento ocasionadas pela articulação entre a erosão originada por escoamento de água superficial concentrado e subsuperficial, com erosão interna (piping). Desenvolvem-se por deslizamento lateral de paredes (auxiliado por subpressões em trincas de descompressão) e erosão remontante por vezes com abatimentos súbitos de terreno (PONÇANO \& PRANDINI, 1987).

Atuam preferencialmente sobre depósitos arenosos semi ou inconsolidados, em que a fase inicial do ravinamento atinge principal- mente solos do tipo podzólico vermelhoamarelo orto.

A possível razão do fenômeno ocorrer nesses solos está ligada à sua susceptibilidade relativa à erosão em face do seu baixo grau de compactação, uma vez que, tratando-se de sedimentos recentes, sofreram menor diagênese.

A prevenção e correção de boçorocas têm seu sucesso ligado diretamente à diagnose do problema, com a realização de estudos geológicos, geomorfológicos e principalmente geotécnicos das áreas afetadas e a caracterização da dinâmica do seu processo de evolução.

Estudamos no presente trabalho uma boçoroca localizada no município de São Pedro, situado na região centro-leste do Estado de São Paulo (FIGURA 1), através da caracterização geotécnica dos sedimentos onde ela ocorre (SANTORO, 1991).

\section{CONSIDERAÇÕES GERAIS}

As boçorocas não são feições típicas dos depósitos sedimentares modernos, porém 
podemos afirmar que ocorrem, preferencialmente, em tais sedimentos (RODRIGUES, 1982; 1984). Excetuando-se raros fenômenos erosivos encaixados em solos de rochas cristalinas, a grande maioria das boçorocas - inclusive a analisada neste trabalho - está associada aos depósitos modernos, entendendo-se como sedimentos modernos (recentes ou neocenozóicos) todos os que se enquadram na proposição de BJORNBERG \& LANDIM (1996). Segundo estes autores, no interior do Estado de São Paulo constituem uma cobertura sedimentar de espessura variável que capeia superfícies marcantemente aplainadas.
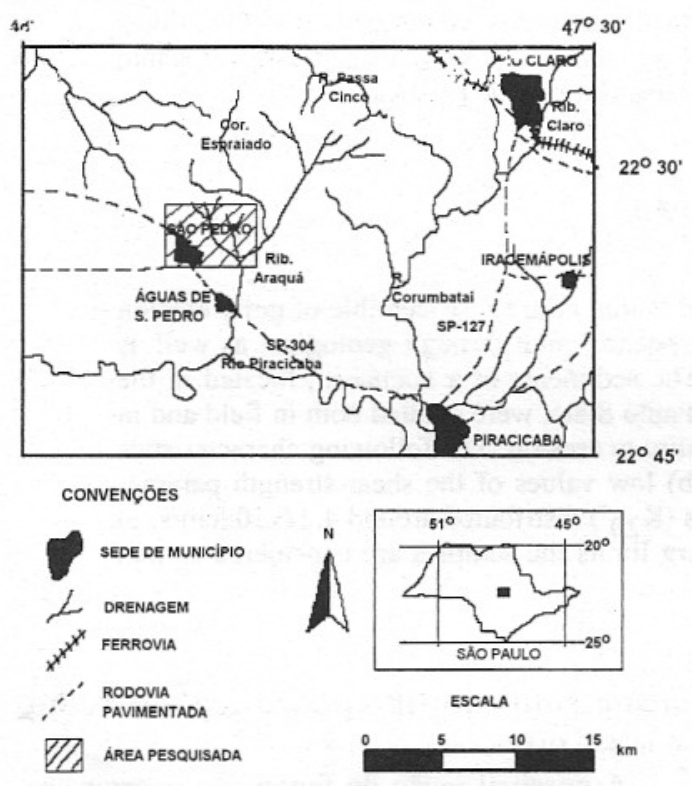

FIGURA 1 - Localização da Área e Acessos.

Pela distribuição granulométrica, os sedimentos estudados assemelham-se extremamente ao Arenito Botucatu (Eocretáceo). Entretanto, a fração grosseira e os valores das medianas, indicadores de maior competência do veículo de transporte, a maior percentagem de magnetita presente, as estruturas primárias de deposição e a presença de restos vegetais são características extremamente valiosas na diferenciação de ambos sedimentos.

Tal deposição pós-cretácica efetuou-se obedecendo a uma drenagem com traçado semelhante ao atual e provavelmente em clima semiárido, com flutuações para fases climáticas mais úmidas.

Os autores mencionados propõem para os depósitos sedimentares encontrados na bacia do Rio Piracicaba, a uma altitude de $600-800 \mathrm{~m}$, a designação estratigráfica de Formação Rio
Claro (Neocenozóica) com secção-tipo em Rio Claro (SP).

Não foi executado um levantamento geológico detalhado da área investigada pois este trabalho tem como objetivo, sobretudo, apresentar uma caracterização geotécnica dos sedimentos cenozóicos que ocorrem nos terrenos afetados pela boçoroca analisada. Tal caracterização baseou-se no estabelecimento de alguns parâmetros físicos desses sedimentos, visando a evidenciar seu nível de influência sobre o processo erosivo estudado. Foi feito, no entanto, um reconhecimento de semidetalhe no interior da boçoroca e em áreas próximas adjacentes (SANTORO, 1991).

Os critérios que nortearam a seleção da área, ou seja, o estudo desta boçoroca, foram principalmente os seguintes:

2.1 Estágio evolutivo da erosão e dimensões - A boçoroca mostra todas as fases evolutivas do fenômeno e pelas suas dimensões, tratase de uma das maiores dentre as conhecidas no Estado de São Paulo, tanto em área de ocorrência como em comprometimento da região envolvida.

2.2 Tipo de sedimento - Em São Pedro as áreas mais afetadas pela erosão acelerada são aquelas onde é destacada a presença de sedimentos cenozóicos extremamente arenosos.

2.3 Perfil estratigráfico - A boçoroca analisada é caracterizada pela presença de duas formações geológicas distintas, representadas pelos sedimentos modernos que ocorrem capeando os arenitos da Formação Pirambóia, mais antiga.

\section{OBSERVAÇÕES E TRABALHOS DE CAMPO}

Executamos um reconhecimento geológico semidetalhado somente no interior da boçoroca estudada e áreas adjacentes e nos preocupamos em observar as feições mais características associadas aos processos erosivos, como fenômenos de alívio de tensões, estruturas de abatimento, paredes, cabeceiras e fundo da boçoroca, forma da encosta, etc. (SANTORO, op. cit.).

\subsection{Coleta de amostras}

Dois tipos de amostras foram coletadas visando à investigação de suas propriedades geotécnicas: as deformadas e as indeformadas. 
Foram coletadas 5 amostras deformadas, retiradas das paredes laterais dos taludes principais da boçoroca estudada, de locais e profundidades diferentes e distribuídas ao longo de seu ramo principal, de modo que todo ele fosse contemplado com a amostragem. Somente foram amostrados sedimentos pertencentes aos depósitos modernos.

Também foram coletadas 5 amostras indeformadas, distribuídas ao longo do ramo principal da boçoroca e retiradas das paredes laterais de seus taludes principais.

Os locais e as profundidades foram variáveis, porém somente retiradas dos depósitos modernos. Duas amostras foram coletadas em profundidades semelhantes, $1,70 \mathrm{~m}$ e $2,00 \mathrm{~m}$, já que foram usadas nos ensaios de Compressão Triaxial o que permitiu para ambas, no momento do ensaio, a adoção de valores baixos de Tensões Confinantes, uma vez que, nestas profundidades, os materiais também estavam submetidos a baixas Tensões de Confinamento.

\subsection{Levantamentos gerais e descrições das características da boçoroca}

A boçoroca localiza-se aproximadamente a 2,0 km a SE do sítio urbano de São Pedro, nas cabeceiras do Córrego Tuncum, afluente do Ribeirão Araquá, no local denominado Recanto das Águas, no bairro Jardim São Dimas, de coordenadas E Q 204 e N S 7504. Apresenta no seu ramo principal como dados geométricos mais expressivos, $700 \mathrm{~m}$ (estimados) de largura máxima, profundidade máxima de $60 \mathrm{~m}$ e comprimento estimado de $1.000 \mathrm{~m}$ (FIGURAS 1-2).

A área apresenta um relevo suave, sob a forma de colinas, com encostas convexas, esculpidas em rochas sedimentares da Formação Pirambóia. As vertentes possuem declives predominantes entre $7^{\circ}$ e $10^{\circ}$, podendo chegar até $22^{\circ}$, raramente maiores. Os valores altimétricos variam de 400 a 710 metros.

Os arenitos da Formação Pirambóia ocupam a maior parte da região de São Pedro. Formam encostas em dissecação, patamares resultantes da resistência diferencial à erosão, constituindo terraços estruturais que podem ser confundidos com terraços fluviais.

A intensa meteorização destes arenitos originou solos arenosos espessos, bastante permeáveis, do tipo podzólico vermelho-amarelados abruptos e areias quartzosas que nas pro- ximidades da cidade de São Pedro e junto ao vale do Rio Piracicaba atingem, em média, espessuras de 15 a 20 metros. Nessas áreas, a densidade de drenagem é muito baixa, apresentando cursos d'água com vales alongados.
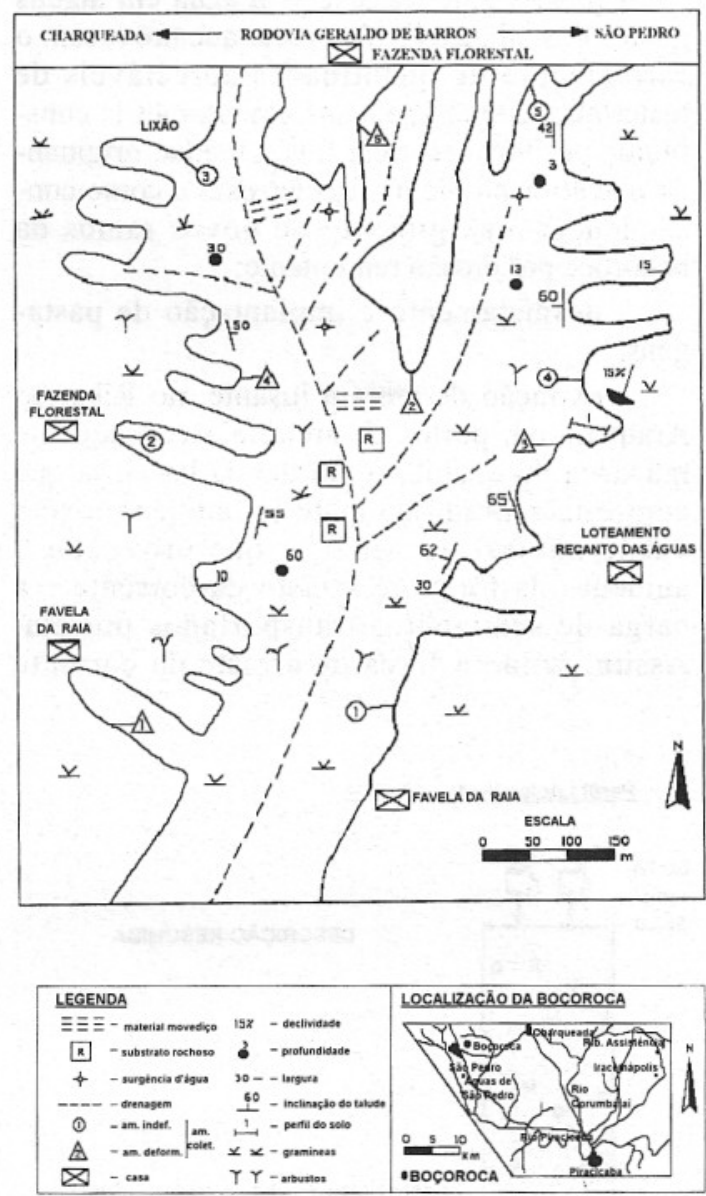

FIGURA 2 - Croqui da Boçoroca e do Uso e Ocupação Local.

Nota-se na parte norte e central do município de São Pedro, no domínio da Formação Pirambóia, o fenômeno da erosão acelerada, identificado através da presença de boçoroca como esta, que afeta os sedimentos modernos sobrejacentes àquela formação (FIGURA 3).

Quanto à ocupação do solo nos arredores da boçoroca, temos a montante, presença de loteamentos de baixa renda, favelas e pastos e, a jusante das cabeceiras, pasto (FIGURA 2).

Com relação às causas principais, responsáveis pelo surgimento desta boçoroca, podemos destacar: 
- inexistência de obras de adução e captação de águas pluviais, guias e asfalto nas ruas dos arredores da boçoroca;

- loteamentos sem infra-estrutura, com obras terminais de drenagem executadas de forma inadequada e a conseqüente concentração do escoamento superficial em direção à boçoroca;

- presença de surgências d'água em alguns pontos dos taludes da boçoroca, que provocam o carreamento de quantidades apreciáveis de material, facilitado pela sua granulometria constituída por $90 \%$ de areia fina a média, originando o abatimento de massas terrosas e como conseqüência o surgimento de novos ramos da boçoroca por erosão remontante;

- desmatamento e implantação de pastagens;

- extração de areia a jusante, no Ribeirão Araquá, com portos de areia, e a conseqüente mudança do equilíbrio hídrico da bacia, já que com esta retirada de material aumentou-se a vazão natural do canal, o que provocou o aumento da força de arrasto da corrente e a carga de sedimentos transportados por ela. Assim, sendo a força de arraste da corrente

\section{Perfil Litológico 1}

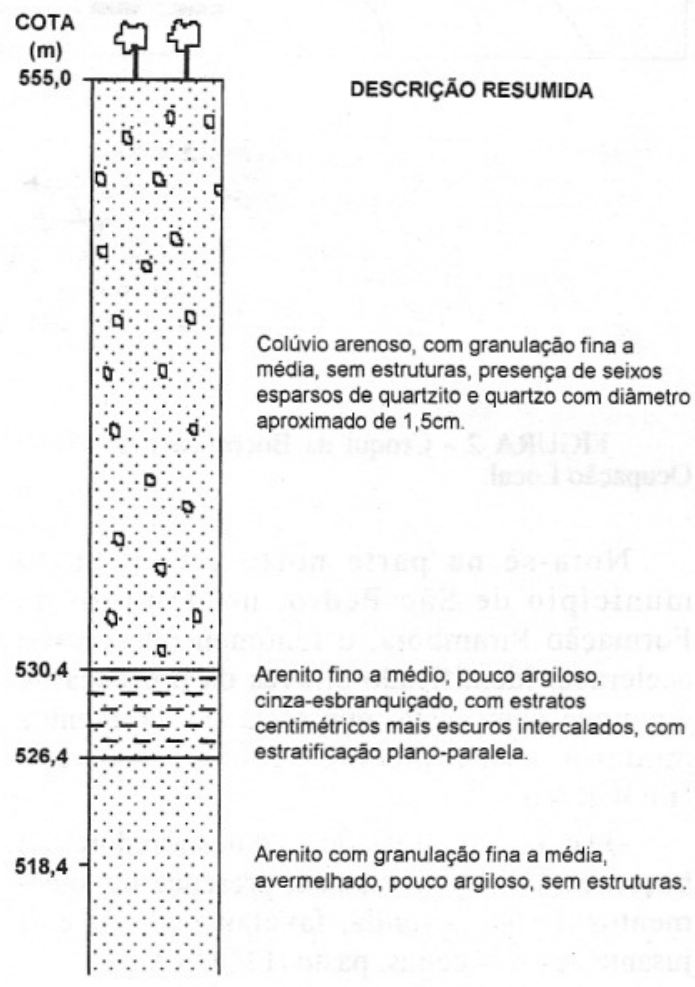

FIGURA 3 - Perfil Litológico Típico da Boçoroca de São Paulo. superior à necessária ao transporte da carga sólida conduzida pela água, houve um incremento da erosão e o leito do curso d'água continuou se aprofundando.

Em resumo, a dinâmica de evolução da boçoroca se caracteriza por uma erosão remontante em cabeceiras de drenagem, ativada pela concentração do escoamento das águas pluviais oriundas das ruas dos loteamentos que margeiam a boçoroca, surgências d'água com instabilidade e desmoronamentos dos taludes do corpo principal (SANTORO, op. cit.).

\section{ENSAIOS DE LABORATÓRIO E RESULTADOS OBTIDOS}

Foram efetuados vários ensaios de laboratório em amostras coletadas na boçoroca estudada, tanto de caracterização do material, como ensaios específicos, com o objetivo de determinar certas propriedades dos sedimentos que estejam relacionadas com os fenômenos erosivos (SANTORO, op. cit.).

Desta forma, dentre os ensaios de caracterização do material, realizamos a Análise Granulométrica, Determinação de Índices Físicos, Limites de Atterberg e Peso Específico dos Sólidos.

Dentre os ensaios específicos, realizamos ensaios de Compressão Triaxial Rápido (sem qualquer drenagem do corpo de prova) e de Permeabilidade.

4.1 Análise granulométrica - Os sedimentos das 5 amostras analisadas, conforme a norma ABNT - MB-32/77, mostram características granulométricas praticamente iguais, ou seja, extremamente arenosos, com porcentagem de areia em torno de $90 \%$ e apenas $10 \%$ de material fino. A curva expressa na FIGURA 4 representa o resultado da análise granulométrica de uma amostra coletada e a TABELA 1 apresenta os parâmetros estatísticos segundo FOLK \& WARD (1957), para as 5 amostras estudadas.

4.2 Índices físicos, Limites de Atterberg e Peso específico dos sólidos - A TABELA 2 reúne os valores dos parâmetros físicos de cada amostra ensaiada e o respectivo valor médio.

Podemos observar que todas as amostras analisadas apresentam uma elevada porosidade, com valor médio de $42 \%$, um alto índice de vazios, com valor médio $0,731 \mathrm{e}$, como era de se esperar, todas apresentam-se como não plásticas. Estas constatações evidenciam que o sedimento cenozóico pesquisado apresenta características físicas que favorecem uma ação erosiva intensa sobre ele. 


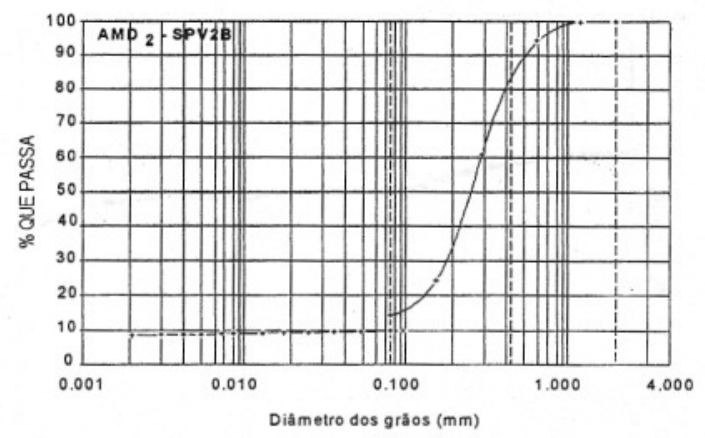

FIGURA 4 - Curva Granulométrica do sedimento da Amostra $\mathrm{AMD}_{2}$ da Boçoroca de São Pedro. De acordo com o método de peneiramento da fração mais grossa e densitometria dos finos, segundo norma ABNT - MB-32/77.

4.3 Ensaios de permeabilidade - $\mathrm{Na}$ execução desses ensaios, utilizamos o permeâmetro de carga constante e corpos de prova retirados de amostras indeformadas. Os valores médios do Coeficiente de Permeabilidade $(\mathrm{em} \mathrm{cm} / \mathrm{s})$ para a temperatura de $20^{\circ} \mathrm{C}\left(\mathrm{K}_{20}\right)$ e suas variações com o número de dias, para cada amostra ensaiada, estão expressos na TABELA 3.

Os ensaios de permeabilidade permaneceram montados durante 9 dias, para que fosse possível verificar também eventuais variações
TABELA 1 - Parâmetros Estatísticos de FOLK \& WARD (1957), dos Sedimentos Estudados da Boçoroca.

\begin{tabular}{|c|c|c|c|c|}
\hline $\begin{array}{r}\text { PARÂMETROS } \\
\text { ESTATÍSTICOS }\end{array}$ & $\mathrm{M}_{\mathrm{Z}}$ & $\sigma_{\mathrm{I}}$ & $\mathrm{SK}_{\mathrm{I}}$ & $\mathrm{K}_{0}$ \\
AMOSTRAS & 2,34 & 1,45 & 0,47 & 3,13 \\
\hline $\mathrm{SP}-\mathrm{AM}_{1}$ & 2,35 & 1,49 & 0,48 & 3,15 \\
\hline $\mathrm{SP}-\mathrm{AM}_{2}$ & 2,38 & 1,46 & 0,50 & 3,10 \\
\hline $\mathrm{SP}-\mathrm{AM}_{3}$ & 2,39 & 1,43 & 0,49 & 3,11 \\
\hline $\mathrm{SP}-\mathrm{AM}_{4}$ & 2,37 & 1,47 & 0,51 & 3,12 \\
\hline $\mathrm{SP}-\mathrm{AM}_{3}$ & 2,37 & 1,46 & 0.49 & 3,12 \\
\hline $\mathrm{MEE} D I A$ & &
\end{tabular}

do coeficiente medido. Tal coeficiente diminuiu nas cinco amostras analisadas, com valor máximo de $5,30 \times 10^{-3} \mathrm{~cm} / \mathrm{s}$ para amostra 1 e valor mínimo de $3,40 \times 10^{-3} \mathrm{~cm} / \mathrm{s}$, para a amostra 3 . O GRÁFICO 1 mostra a variação do coeficiente de permeabilidade $(\mathrm{em} \mathrm{cm} / \mathrm{s})$ com o número de dias para a amostra 1 .

Este fato sugere um carreamento de partículas finas do topo para a base do corpo de prova, onde possivelmente elas se concentraram e difi-

TABELA 2 - Valores dos Parâmetros Físicos de cada Amostra Analisada e o Respectivo Valor Médio, para a Boçoroca de São Pedro.

\begin{tabular}{|c|c|c|c|c|c|c|}
\hline & $\mathrm{AM}_{1}$ & $\mathrm{AM}_{2}$ & $\mathrm{AM}_{3}$ & $\mathrm{AM}_{4}$ & $\mathrm{AM}_{5}$ & $\begin{array}{c}\text { VALOR } \\
\text { MÉDIO }\end{array}$ \\
\hline$\gamma_{\left(\mathrm{g} / \mathrm{cm}^{3}\right)}$ & 1,395 & 1,612 & 1,653 & 1,611 & 1,590 & 1,612 \\
\hline $\mathrm{W}(\%)$ & 7,011 & 4,633 & 3,801 & 7,071 & 4,837 & 5,470 \\
\hline$\gamma_{\mathrm{d}\left(\mathrm{g} / \mathrm{cm}^{3}\right)}$ & 1,563 & 1,541 & 1,592 & 1,505 & 1,509 & 1,542 \\
\hline$\ell$ & 0,8181 & 0,695 & 0,668 & 0,751 & 0,724 & 0,731 \\
\hline $\mathrm{S}_{\mathrm{r}(\%)}$ & 23 & 18 & 17 & 24 & 16 & 20 \\
\hline $\mathrm{n}(\%)$ & 45 & 41 & 40 & 43 & 42 & 42 \\
\hline $\mathrm{LL}(\%)$ & - & - & -- & - & - & - \\
\hline $\mathrm{LP}(\%)$ & - & - & - & - & - & - \\
\hline $\mathrm{IP}(\%)$ & $\mathrm{NP}$ & $\mathrm{NP}$ & $\mathrm{NP}$ & $\mathrm{NP}$ & $\mathrm{NP}$ & - \\
\hline$\gamma_{\mathrm{s}(\%)}$ & 2,671 & 2,628 & 2,656 & 2,634 & 2,602 & 2,638 \\
\hline
\end{tabular}

\begin{tabular}{|c|}
\hline SIMBOLOGIA \\
\hline $\begin{array}{c}\text { PESO ESPECIFICO DO } \\
\text { SOLO }\end{array}$ \\
\hline TEOR DE UMIDADE \\
\hline $\begin{array}{c}\text { PESO ESPECIFICO DO } \\
\text { SOLO SECO }\end{array}$ \\
\hline INDICE DE VAZIOS \\
\hline GRAU DE \\
SATURAÇÃO \\
\hline POROSIDADE \\
\hline LIMITES \\
DE \\
ATTERBERG \\
\hline PESO ESPECIFICO DOS \\
SÓLIDOS \\
\hline
\end{tabular}


TABELA 3 - Variação do Coeficiente de Permeabilidade com o número de dias, para as Amostras Analisadas da Boçoroca de São Pedro, $\mathrm{em} \mathrm{cm} / \mathrm{s}$.

\begin{tabular}{|c|c|c|c|c|c|}
\hline$N^{N}$ DE DIAS & $\mathrm{AM}_{4}$ & $\mathrm{AM}_{2}$ & $\mathrm{AM}_{3}$ & $\mathrm{AM}_{4}$ & $\mathrm{AM}_{5}$ \\
\hline 1 & $5,30 \times 10^{-3}$ & $4,95 \times 10^{-3}$ & $5,15 \times 10^{-3}$ & $4,19 \times 10^{3}$ & $4,85 \times 10^{-3}$ \\
\hline 2 & $5,20 \times 10^{3}$ & $4,80 \times 10^{3}$ & $4,88 \times 10^{3}$ &,$+ 28 \times 10^{3}$ & $4.68 \times 10^{3}$ \\
\hline 3 & $4,90 \times 10^{3}$ & $4,55 \times 10^{-3}$ & $4,70 \times 10^{-3}$ & $4,07 \times 10^{3}$ & $4,60 \times 10^{3}$ \\
\hline 4 & $4,40 \times 10^{3}$ & $4,35 \times 10^{3}$ & $4,65 \times 10^{3}$ & $4,15 \times 10^{3}$ & $4.29 \times 10^{3}$ \\
\hline 5 & $4,40 \times 10^{3}$ & $4,29 \times 10^{3}$ & $3,95 \times 10^{3}$ & $+.20 \times 10^{3}$ & $4.30 \times 10^{3}$ \\
\hline 6 & $4,30 \times 10^{-3}$ & $4,20 \times 10^{3}$ & $3,80 \times 10^{3}$ & $4.20 \times 10^{3}$ & $4.25 \times 10^{3}$ \\
\hline 7 & $4.29 \times 10^{3}$ & $4.15 \times 10^{3}$ & $3,77 \times 10^{-3}$ & $3.95 \times 10^{3}$ & $4.20 \times 10^{-3}$ \\
\hline 8 & $4,15 \times 10^{3}$ & $3,85 \times 10^{3}$ & $3.60 \times 10^{-3}$ & $3.80 \times 10^{-3}$ & $3,75 \times 10^{-3}$ \\
\hline 9 & $3,65 \times 10^{3}$ & $3.55 \times 10^{3}$ & $3,40 \times 10^{-3}$ & $3.67 \times 10^{3}$ & $3.70 \times 10^{3}$ \\
\hline
\end{tabular}

cultaram o fluxo de água. Porém, o que deve ser observado é que o valor elevado de permeabilidade é compatível com a granulometria predominante dos sedimentos analisados, que apresentam $90 \%$ de areia fina a média e $10 \%$ de material fino.

4.4 Ensaios de compressão triaxial Efetuamos 2 ensaios triaxiais rápidos, não adensados, em corpos de prova retirados de 2 amostras indeformadas da boçoroca analisada.

Neste ensaio o teor de unidade do corpo de prova permaneceu constante, ou seja, com o grau de saturação $(\mathrm{Sr})$ natural das amostras, com valores médios de $20 \%$, sendo as tensões medidas as tensões totais. O corpo de prova cilíndrico é submetido a uma tensão confinante, $\sigma 3$, com aumento gradual da tensão axial, $\sigma 1$, até a ruptura do corpo de prova.

Optamos pelo ensaio de Compressão Triaxial Rápido em função das características físicas do material e dos objetivos da pesquisa. Ou seja, em função dos resultados dos ensaios de índices físicos, granulometria e permeabilidade dos sedimentos analisados, escolhemos o ensaio rápido por acharmos que este método traria os melhores resultados, principalmente por ser o mais versátil para a determinação da resistência ao cisalhamento do solo.

As tensões confinantes $\left(\sigma_{3}\right)$ utilizadas foram de $0,4,0,6$ e $1,0 \mathrm{kgf} / \mathrm{cm}^{2}$ para os dois ensaios. Os dois corpos de prova foram talhados com $5,0 \mathrm{~cm}$ de diâmetro e $12,5 \mathrm{~cm}$ de altura. A velocidade do ensaio foi sempre de $1,13 \mathrm{~mm} /$ minuto.

A adoção de valores baixos de tensões confinantes está relacionada ao fato de os blocos indeformados terem sido coletados a profundidade de $1,70 \mathrm{~m}$ e $2,00 \mathrm{~m}$, onde o material estava submetido também a baixas tensões de confinamento.

As curvas Tensão-Deformação e as

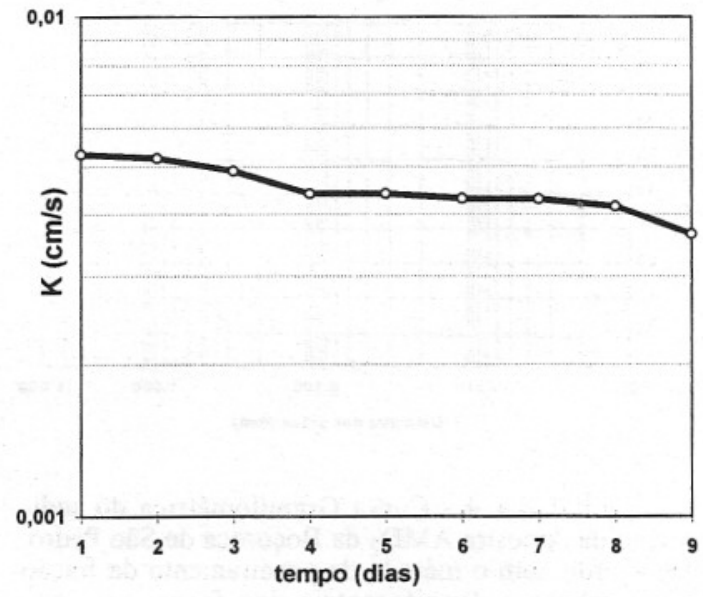

GRÁFICO 1 - Variação do coeficiente de permeabilidade $(\mathrm{em} \mathrm{cm} / \mathrm{s})$ com o número de dias da amostra 1 .

envoltórias de Coulomb-Mohr para as tensões totais dos sedimentos da boçoroca investigada estão expressas nas FIGURAS 5 e 6 . A TABELA 4 mostra as tensões confinantes $\left(\sigma_{3}\right)$ utilizadas, juntamente com o desvio de tensões $\left(\sigma_{1}-\sigma_{3}\right)$, a tensão axial máxima $\left(\sigma_{1}\right)$, a coesão (c) e o ângulo de atrito interno (ø) obtidos a partir dos ensaios realizados.

Analisando-se os resultados obtidos neste ensaio, e os baixos valores de coesão do material, podemos fazer as seguintes observações. As duas amostras indeformadas coletadas para o ensaio estavam a pequenas profundidades $(1,70$ e $2,00 \mathrm{~m})$. Logo, a coesão obtida seria aparente
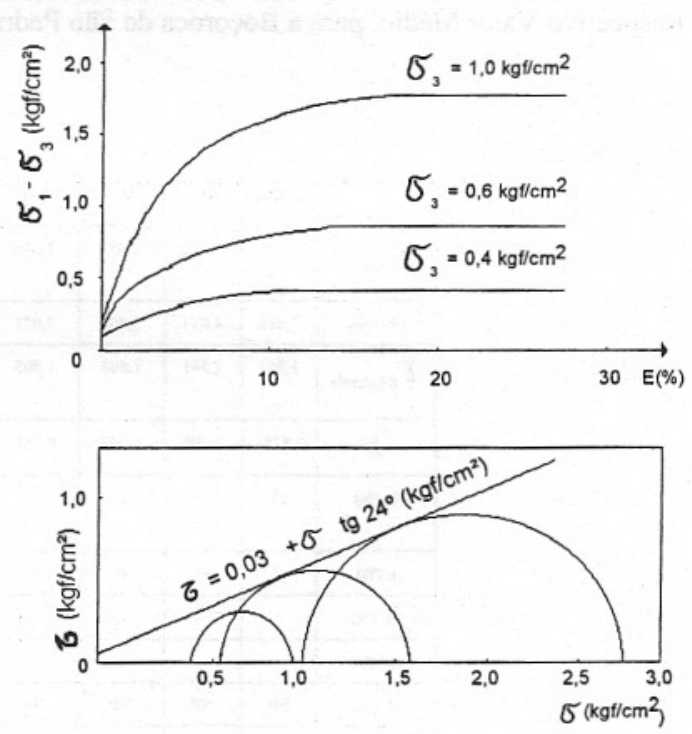

FIGURA 5 - Curvas Tensão-Deformação e Envoltória de Resistência (Q) para o Sedimento da Amostra $\mathrm{AMI}_{2}$ da Boçoroca de São Pedro. 

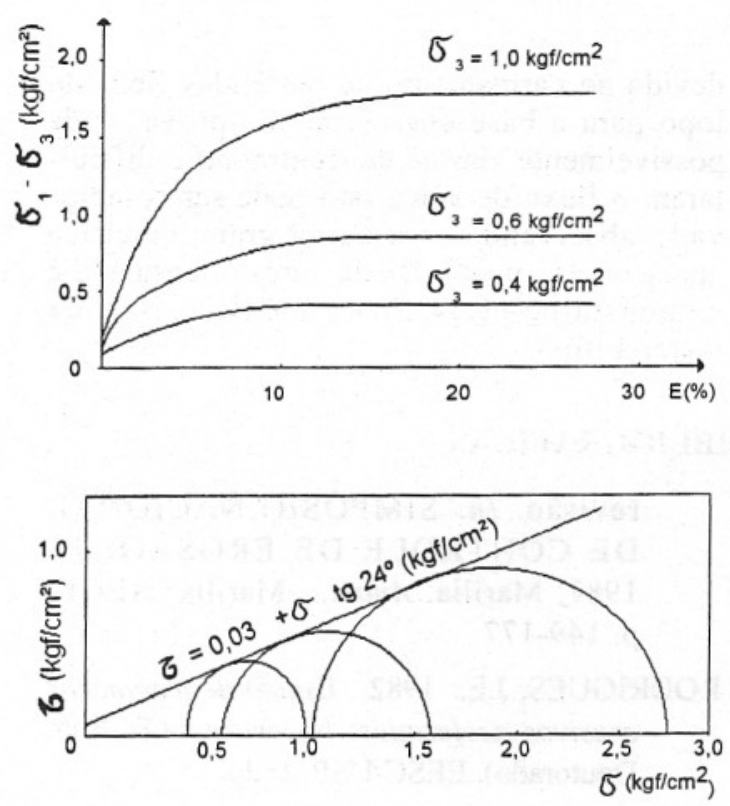

FIGURA 6 - Curvas Tensão-Deformação e Envoltória de Resistência (Q) para o Sedimento da Amostra $\mathrm{AMI}_{4}$ da Boçoroca de São Pedro.

$\left(0,03 \mathrm{kgf} / \mathrm{cm}^{2}\right)$ e $24^{\circ}$ de ângulo de atrito interno é um valor próprio para areias muito fofas.

$\mathrm{O}$ que poderia ter originado estes valores, obtidos para as duas amostras ensaiadas, é a existência de uma pequena cimentação das partículas de areia por sílica, óxidos e hidróxidos de ferro e argilo-minerais.

O desenvolvimento dessa cimentação se deve à mobilização desses elementos pela água que - percola o sedimento e sua ascensão até próximo à superfície do terreno. Tal processo cimentante está associado à alternância entre períodos chuvosos e secos com insolação, com mobilização da sílica, óxidos e hidróxidos de ferro e alguns argilo-minerais, sendo bastante comum a sua ocorrência em solos e rochas de regiões tropicais, onde a pluviosidade é relativamente elevada.

TABELA 4 - Valores Relativos aos dois Ensaios Triaxiais Realizados com Amostras da Boçoroca de São Pedro.

\begin{tabular}{|c|c|c|c|c|c|}
\hline SÃO PEDRO & $\sigma_{2}\left(\mathrm{kgf} / \mathrm{cm}^{2}\right)$ & $\begin{array}{c}\sigma_{t}-\sigma_{g} \\
\left(\mathrm{Kg}^{2} / \mathrm{cm}^{2}\right)\end{array}$ & $\sigma_{1}\left(\mathrm{Kgf} / \mathrm{cm}^{2}\right)$ & $\mathrm{c}\left(\mathrm{Kgf} / \mathrm{cm}^{2}\right.$ & 0 \\
\hline \multirow{3}{*}{$\begin{array}{c}\text { AMOSTRA } \\
\mathrm{AM}_{2}\end{array}$} & 0,4 & 0,56 & 0,96 & & \\
\hline & 0.6 & 0,98 & 1,58 & 0,03 & 248 \\
\hline & 1,0 & 1,81 & 2,81 & & \\
\hline \multirow{3}{*}{$\begin{array}{c}\text { AMOSTRA } \\
\mathrm{AM}_{4}\end{array}$} & 0,4 & 0,58 & 0,98 & & \\
\hline & 0,6 & 0,93 & 1,53 & 0,03 & 248 \\
\hline & 1,0 & 1,75 & 2,75 & & \\
\hline
\end{tabular}

\section{CONCLUSÕES}

Em função dos trabalhos realizados e dos parâmetros analisados, pôde-se chegar aos seguintes resultados:

a) o caráter extremamente arenoso e friável, a elevada porosidade (valor médio de $42 \%$ ), índices de vazios relativamente altos (valor médio de 0,734$)$, valores de coesão praticamente nulos $\left(0,03 \mathrm{kfg} / \mathrm{cm}^{2}\right)$ e baixos valores do ângulo de atrito interno $\left(24^{\circ}\right)$ dos sedimentos da boçoroca estudada, favorecem os fenômenos de erosão superficial. Os fenômenos de arrasto de partículas pelo lençol freático e de liquefação dos sedimentos na base dos taludes da boçoroca, são eventos importantes para explicar a sua evolução lateral;

b) a inexistência de obras de adução e captação de águas pluviais, guias e asfalto das ruas nos arredores da boçoroca, aliadas à suscetibilidade do terreno à erosão, são fatores importantes no desenvolvimento desta boçoroca;

c) os loteamentos sem infra-estrutura, à margem da boçoroca, com obras terminais de drenagens executadas de forma inadequada e a conseqüente concentração do escoamento superficial ao longo dos maiores declives da área e em direção à boçoroca são elementos que contribuem para o rápido aumento da área afetada, com o alargamento e alongamento da macro-ravina;

d) a intervenção humana, que se dá através do desmatamento e implantação de pastagens, constitui-se em fator desencadeador e decisivo na aceleração dos processos erosivos;

e) a boçoroca de São Pedro ocorre em encosta convexa coletora e a declividade da área está entre $15 \%$ e $17 \%$;

f) a boçoroca de São Pedro apresenta uma rápida evolução e grandes dimensões por apresentar, além de outros fatores importantes, um fluxo de água por interceptação do lençol freático;

g) a ação das águas subterrâneas associada à concentração do escoamento superficial, contribui para o desenvolvimento da boçoroca;

h) as análises granulométricas realizadas mostram que os sedimentos onde ocorre a boçoroca apresentam granulação com porcentagem de areia fina a média em torno de $90 \%$ e porcentagem de finos em torno de $10 \%$, diâmetro médio $\left(\mathrm{M}_{\mathrm{Z}}\right)$ de 2,37, desvio padrão $\left(\sigma_{\mathrm{I}}\right)$ de 1,46 e assimetria $\left(\mathrm{Sk}_{\mathrm{I}}\right)$ e curtose $\left(\mathrm{K}_{\mathrm{G}}\right)$, respectivamente de 0,49 e 3,12 ;

I) os sedimentos da boçoroca apresentam homogeneidade granulométrica e valores de permeabilidade variando de $3,40 \times 10^{-3} \mathrm{~cm} / \mathrm{s}$ a 
$5,30 \times 10^{-3} \mathrm{~cm} / \mathrm{s}$ e portanto compatíveis com a granulometria predominante que é em torno de $90 \%$ de areia fina a média;

j) diminuição nos valores dos coeficientes de permeabilidde, em todos os ensaios realizados, à medida em que os dias foram passando. A diminuição destes valores ocorreu devido ao carreamento de partículas finas do topo para a base dos corpos de prova, onde possivelmente elas se concentraram e dificultaram o fluxo de água. Isto pode ser comprovado observando-se a curva granulométrica apresentada, onde $90 \%$ da amostra enșaiada é composta de areia fina a média e $10 \%$ de material fino.

\section{REFERÊNCIAS BIBLIOGRÁFICAS}

BJORNBERG, A.J.S. \& LANDIM, P.M.B. 1966. Contribuição ao estudo da Formação Rio Claro (Neocenozóico). São Paulo: SBG, Bol. Soc. Bras. Geol. 15(4): 43-48.

DEPARTAMENTO DE ÁGUAS E ENERGIA ELÉTRICA \& INSTITUTO DE PESQUISAS TECNOLÓGICAS DO ESTADO DE SÃO PAULO. 1990. Controle de erosão: bases conceituais e técnicas; diretrizes para o planejamento urbano e regional; orientações para o controle de boçorocas urbanas. São Paulo, 92p.

FOLK, R.L. \& WARD, W.C. 1957. Brazos river bar: a study in the significance of grain size parameters. Journal of Sedimentary Petrology, 27: 9-16.

PONÇANO, W.L. \& PRANDINI, F.L. 1987. Boçorocas no Estado de São Paulo: uma revisão. In: SIMPÓSIO NACIONAL DE CONTROLE DE EROSÃO, 4., 1987, Marília. Anais... Marília: ABGE, p. 149-177.

RODRIGUES, J.E. 1982. Estudo de fenômenos erosivos acelerados: boçorocas. (Tese de Doutorado). EESC-USP, 162p.

RODRIGUES, J.E. 1984. Estudo geotécnico de fenômenos erosivos acelerados (boçoroca). In: CONGRESSO BRASILEIRO DE GEOLOGIA DE ENGENHARIA, 4., 1984, Belo Horizonte. v.2, p. 169-182.

SANTORO, J. 1991. Fenômenos erosivos acelerados na Região de São Pedro-SP. Estudo da fenomenologia, com ênfase geotécnica. (Dissertação de Mestrado). IGCE-UNESP, Rio Claro. 140p.

Jair Santoro - Instituto Geológico /SMA, Av. Miguel Estéfano, 3.900, Caixa Postal 2972, CEP 04301-903, São Paulo, SP, Brasil.

Vicente José Fulfaro - Instituto de Geociências e Ciências Exatas/UNESP, Av. 24-A n 1.515, Campus da Bela Vista, Caixa Postal 178, CEP 13506-900, Rio Claro, SP, Brasil. 